\title{
The Relationship Between Leaders' Emotional Intelligence and Employee Engagement: An Empirical Study from the Kingdom of Bahrain
}

\author{
Alaa Abdulla $^{1 *}$, Ammar Ahmed ${ }^{2}$, Nadeem Khalid ${ }^{3}$ \\ * Student, Gulf University, Kingdom of Bahrain. \\ ${ }^{2}$. Assistant Professor, Institute of Southern Punjab, Multan, Punjab, Pakistan. \\ ${ }^{3}$ Associate Dean, KIMEP University, Kazakhstan.
}

\author{
Article Info \\ Article history: \\ Received 21 December 2019 \\ Received in revised form 10 January 2020 \\ Accepted 07 March 2020 \\ Published 01 April 2020
}

\begin{abstract}
This study aims to examine the relationship between leaders' emotional intelligence and employee engagement in the private sector of Kingdom of Bahrain. Engaging in creativity in corporations inevitably creates tension, conflict, and emotionally charged debates and disagreements because complex companies want both control and predictability and creativity and change. We endorse those leaders. In particular, leaders' emotional intelligence plays an indispensable function in enabling and aiding employee engagement through four dimensions of emotional intelligence. The data collection method of the study involves quantitative data analysis. Primary data was used in the form of simple random sampling in order to gather enough data to be analyzed for the purpose of the research. A total of 117 questionnaires were submitted, though only 108 were viable to be used in the study. This study's regression model has four predictors; self-awareness, self-regulation, motivation, and self-skills, to the dependent variable, employees' engagement. Results indicate that $67.0 \%$ of the variation in the dependent variable is explained by the proposed model. Moreover, path coefficient findings show that the four independent variables have significant relationships. Self-awareness $(\mathrm{SA})$ has the strongest significant relationship with a $\mathrm{p}$-value $=0.000$ and path coefficient $=0.679$; self-skills $(\mathrm{SS})$ has the second significant relationship with $\mathrm{p}$-value $=0.000$ and path coefficient $=0.318$; self-regulation $(\mathrm{SR})$ has the third significant relationship with $\mathrm{p}$-value $=0.000$ and path coefficient $=0.177$; and motivation $(\mathrm{MO})$ has the least significant relationship with p-value $=0.020$ and path coefficient $=0.109$.
\end{abstract}

Keywords: Employee Engagement, Leaders' Emotional Intelligence, Leadership, Kingdom of Bahrain

\section{Introduction}

Emotional intelligence has become increasingly popular as a measure for identifying potentially effective leaders and as a tool for developing effective leadership skills (Alzyoud et al., 2019). Despite this popularity, however, little empirical research substantiates the efficacy of emotional intelligence in these areas (AlZgool, 2020). The aim of the present paper was to explore the relationship between emotional intelligence and effective leadership. Findings from previous surveys show that engaged employees at work in Gulf Cooperation Council rates are low as compared to other countries in the world. The research refers to 54\% of employees who are engaged in their work, which means that 1 out of two employees is engaged in the organization. Women reported as they practice the lower engagement level, especially among the new generation.

Bahrain stated as the second-lowest engaged country in GCC, 49\%, where the Unites Arab Emirates stated as the highest, 46\% (Qudurat). In another case, the Tower Watson Global Workforce study 2012 on workers from around the world shows that only $35 \%$ of employees are engaged. This low rate is due to different factors that employees believe in them, and they exist in the workplace, which affects the rate of employee engagement, like work pressure, retirement, salary rate, and job security. Nowadays, in Bahrain's business environment, many problems have originated in different aspects. These problems will ultimately affect the overall performance of employees, organizations, and the economy as a whole. Having engaged human capital is considered as a foundation stone to the organization and business environment enhancement and development. Unfortunately, we are facing a low rate of employee engagement in Bahrain that requires spotting the light in the internal and external factors that affect employee engagement in the workplace. According to Wambura (2020), employee engagement is an active state in which workers are dedicated to performing excellently at their place of work and have a feeling of confidence in their own effectiveness.

Furthermore, Mäkikangas et al. (2017) have a unique definition of engagement, which is defined as a positive, workrelated, and fulfilling state of mind attributed to bold dedication, vigor, and absorption. It is depicted as an attentive persistence and unescapable affective-cognitive state that have a relative focus on any specific object, individual, event, 
and action. Prins (2006) asserts that work engagement is established on the grounds of three critical dimensions, which entail absorption, dedication, and vigor. In regard to vigor, it is associated with extreme echelons of energy as well as mental suppleness; hence it is the ability to willingly invest effort in work and consequently discourage laziness or the feeling of relentlessness. Therefore, it bolstered persistence even in adverse circumstances. Dedication under employee engagement is the process in which a worker's task is considered substantial, and he or she is attributed to a sense of enthusiasm and proud, particularly for their job. In this case, dedication is attributed to the position of finding one's work more significant and feels passionate about what they find useful for their job. On the other hand, absorption is maintaining a high level of happy attachment in a specific task in the organization.

Kahn (1990) claimed that employee engagement is the instantaneous involvement as well as the manifestation of one's preferred self in role actions that are directed to advance connections to work and relate with other people. It also encompasses the unique presence that constitutes cognitive, physical, and emotional, which promote absolute role performance. There are also confident assertions that put into account the psychological situations as contributing to the engagement process. Employee engagement is characterized based on factors such as passion, involvement, and enthusiasm. Engaged employees are determined to showcase the commitment towards achieving success to the organization. This engaged commitment is significantly influenced by the management's ability to motivate a robust desire for optimality in their work processes. The ability and willingness of an individual to channel contribution towards organizational success are what categorizes employee engagement.

Employee Engagement is defined as a stage where employee loyalty, both sentimental and logical, remains in relation to gaining the organization's objective. An organization's talent toward reaching its goals and objectives counts on the competence of Employee Engagement plans. Subsequently, it demands huge delineation and attention to design and implements Employee Engagement planning. Engaged employees have a strong emotional relationship with the organization. Employees' participation in company enormous actions, pedagogical changes, and unlock connections are considered animated materials for Employee Engagement (Gupta, 2015). Employee engagement has to grow to be a warm theme in current years among consulting firms and in the popular commercial enterprise press. However, worker engagement has not often been studied in the academic literature, and highly little is known about its antecedents and consequences. The reason for this study used to be to take a look at a mannequin of the antecedents and consequences of job and organization engagements based on social exchange theory. Leaders' Emotional Intelligence is linked to employee engagement. Transformational leaders will make tomorrow better through four different ways: vision, authenticity, growing mindsets, and creativity (LEADERSHIP \& DERINDAG, 2020). Through vision, the commitment creates a noble vision towards work to encourage others (Mozammel et al., 2018). Authenticity involves being authentic to them to the mission, not to personal benefits only, but they inspire the team to give their best. Through growing mindsets, they motivate their team professionally and offer personal commitment where they invest time and energy in their employees. Finally, through creativity, they encourage their team members to innovate and create new ideas in the workplace to enhance their satisfaction and performance. Managers who have the emotional intelligence skill can market the organization outcome and lead the continuous success. The vision that leadership is an important asset in the organization to guide the follower-ship; this concept may refer to an organization without skilled managers may be ruined and not be able to reach their organizational goals and objectives. The unlimited changes required good knowledge and experienced managers to prevent the destruction of the workflow (Al-Maamari et al., 2018). As Clarke (2018) stated that: "Leadership researchers had struggled for most of the last century to put together an integrated, theoretically cohesive view of the nature of leadership." Nevertheless, a better and promising picture of leadership has begun to surface in the last two decades, and studies have been revived in many fields that were considered as lacking in the aspect of consistency. However, an analysis of existing leadership literature reveals that a lot of the study on the initial "behavioral" school was integrated into "new" research on leadership method (Hoch et al., 2018). Further, theories of the "new" leadership school, such as charismatic and transformational leadership theory, evidently stressed upon the categories of behavior (e.g., compelling manners, transactional manners) that envisage leadership efficacy. The role of a leader is crucial in organizations to set the future of the organizational and its employees.

Therefore, this research aims to examine the relationship between leaders' emotional intelligence and employee engagement. In particular, the study examined whether the self-awareness of managers (defined as an agreement between self and other leadership ratings) would moderate relationships between (a) aspects of emotional intelligence and transformational leadership behavior and (b) transformational leadership behavior and managerial performance. The results of the study revealed that there is a significant relationship between leaders' emotional intelligence and employee engagement. Effective leaders were distinguished as individuals who showed a transformational as opposed to transactional initiative style as estimated by the multifaceted initiative poll. Enthusiastic knowledge is associated with a few transformational initiatives, proposing that it might be a significant segment of a compelling initiative. Specifically, passionate knowledge may represent how successful pioneers screen and react to subordinate $\mathrm{s}$ and make them feel at work. 


\section{Literature Review}

In recent years, there has been a great deal of interest in employee engagement. Many have claimed that employee engagement predicts employee outcomes, organizational success, and financial performance (e.g., total shareholder return) (Alzgool, 2019; Turner, 2019; Zhou et al., 2018). At the same time, it has been reported that employee engagement is on the decline, and there is a deepening disengagement among employees today (Turner, 2019; Zhou et al., 2018). Unfortunately, much of what has been written about employee engagement comes from the practitioner literature and consulting firms. There is a surprising dearth of research on employee engagement in the academic literature (Rao, 2017). The purpose of this study was to investigate the antecedents and consequences of two types of employee engagement: job and organization engagements. Previous research has focused primarily on engagement in one's job. However, there is evidence that one's degree of engagement depends on the role in question (Namubiru, 2019). Thus, it is possible that the antecedents and consequences of engagement depend on the type of engagement.

\subsection{Leaders' Emotional Intelligence}

During the last decade, interpersonal skills have become more integral to effective leadership (Goleman, 1998). Where leaders were once seen to control, plan and inspect the overall running of an organization, in today's more service-oriented industries, leadership roles are also to motivate and inspire others, to foster positive attitudes at work, and to create a sense of contribution and importance with and among employees (Choudhary et al., 2017). These contemporary leadership requirements have placed new demands on leadership training programs to develop these skills in evolving leaders and organizations involved in leadership selection to identify potential candidates (Schoemaker et al., 2018). As a result, research has been exploring the underlying attributes and behaviors of leaders who successfully perform these contemporary leadership roles in order to identify leadership selection and training criteria for the recruitment and development of effective leaders (Buil et al., 2019)

According to Wen et al. (2019), the overall intelligence constitutes both emotional intelligence and cognitive intelligence, which is perceived as a personal intelligence as the antecedent of emotional intelligence. (Prins, 2006) proposed that the concept of emotional intelligence has a bold purpose of understanding and connecting to the self and others through coping adequately with the immediate atmosphere. Wen et al. reiterate that emotional intelligence reflects on the capacity to manage the immediate context through the application of the present knowledge and information. In essence, it tends to measure one's typical sense and the ability to adapt to the world's necessities. Understanding the concept of emotional intelligence requires one to comprehend the processes of emotions. Typically, passion is defined as the internal processes that synchronize several psychosomatic subsystems encompassing cognition, physiological reactions as well as cognizant mindfulness. Intelligence is also the ability of a person to embody information mentally, solve issues, and process data to the most significant extent. In the psychology context, knowledge is defined as the capacity to calculate, learn quickly, reason, and perceive relationships and equivalences. It also involves storing information, retrieving data, using linguistic confidently as well as generalizing and reassessing processes to fit new situations as far as work is a significant factor. Hence, basing on the two concepts, emotions, and intelligence, the theme of emotional intelligence is evaluated and pursued substantially in the organizational context. In simple terms, emotional intelligence is defined as the intellectual utilization of emotions to configure such feelings to work and influence actions and behaviors and rationale in a manner that enhances substantial results. According to Goleman (2001), emotional intelligence is the measure of the extent to which an individual can significantly apply all-encompassing decisions as well as reasoning to specific situations in the course of determining an emotional reaction to specific work situations. Also, Johnson \& Hackman (2018) connects emotional intelligence to higher levels of personal mastery and upholds that emotional intelligence that permits scanning through adoptions in order to facilitate efficient and effective rational decision-making.

\subsection{Emotional Intelligence}

According to Goleman (2001, p.27), emotional intelligence is defined as a cultured potentiality that is based on sensitive information that consequent to a solid performance in the working environment. In particular, Goleman (2001) integrated other people's work to arrive at a standard definition of emotional intelligence, which is discoursed as the ability to supervise and control one's feelings and, which are primarily utilized to provide guidance on the thinking process and activities. This process is directing a common understanding of how aptitudes, which matters a lot in the work life. The adaptation encompasses five-basic emotional as well as social competencies, which are explained below:

- Self-awareness- It is a typical understanding of people feel. Under this segment, people attributed to high emotional intelligence are characterized as being self-aware. Such characters tend to understand their emotions; hence they never allow their feeling to rule and guide them in their work process. People characteristics with self-awareness are always self-confident due to the fact that they trust their predisposition and tend to monitor their emotions not to get out of control. They are honest in all that they are engaged in. The majority of people have a believe that self-awareness is 
the most integral component of emotional intelligence. It is worth noting that emotions influence many our decisionmaking courses, and thus self-awareness is vital in the process of the decision-making process.

- Self-regulation- is also the way of handling robust emotions so that they can facilitate tasks and processes as opposed to interference with such tasks at hand. It is also being meticulous and suspending fulfillment to pursue goals and also recovering proficiently from the emotional anguish.

- Motivation- This is where people's earnest preferences change and guide such people toward their goals. It is an essential process that tends to help take the initiative and a struggle to advance and persevere alongside drawbacks and other many challenges.

- Social skills- This is the way emotions are handled and pursued in associations that are correctly and adequately going through social situations as well as networks, intermingling effortlessly through the utilization of such skills to encourage, lead, convert as well as to avert disputes for purposes of building cooperation as well as teamwork.

According to Goleman's (2001) model of emotional intelligence, it can be best understood as a range of unified emotional as well as social proficiencies and skills that determine the way individuals perceive and express, and comprehend themselves and others. It also showcases the way in which people relate with other people and conform to their daily demands and necessities, pressures, and hurdles to the most significant extent. In short, the Goleman model is enshrined in understanding the value of emotional domains as well as competencies. The model is associated with techniques and competencies that can be used to envisage work routines in a number of many organizational settings in private organizations, particularly in Bahrain. As such, it puts more emphasis on leadership positions. Goleman presents the four essential competencies under clusters of capabilities. Social awareness constitutes such competencies as empathy, political awareness, leveraging diversity, service orientation as well as people's development. Besides, self-regulation entails adaptability, self-control, trustworthiness, conscientiousness, and innovativeness. On the other hand, selfmotivation encompasses initiative, optimism, achievement drive, and commitment. Conversely, social skills are composed of communication, influence, leadership, cooperation and collaboration, conflict management, team potentialities, building bonds, and change catalyst. Emotional intelligence is used to distinguish between people in their feelings and ideas. It supports recognizing interpersonal abilities and explain the right character and activities. EI offers the capacity to differentiate between people's moods, encouragement, and intent. People with high EI levels are eligible to get better results, understand self and counterpart emotions, have a greater empathic ability, and be able to understand self and counterpart emotions. The EI skill is the person's ability to administer emotional sensation in diverse circumstances, which makes people more accepted in society and gives the benefit of being a good negotiator. Furthermore, EI takes the negotiation more advanced to favorable outcomes (Choi et al., 2015).

\subsection{Employee Engagement}

Employee engagement has become a widely used and popular term (Rao, 2017). However, most of what has been written about employee engagement can be found in practitioner journals, where it has its basis in practice rather than theory and empirical research. Rao (2017) noted that there has been surprisingly little academic and empirical research on a topic that has become so popular. As a result, employee engagement appears to be somewhat faddish or what some might call "old wine in a new bottle." To make matters worse, employee engagement has been defined in many ways, and the definitions and measures often sound like other better known and established constructs like organizational commitment and organizational citizenship behavior (Rao, 2017). It has often been defined as an emotional and intellectual commitment to the organization or the amount of discretionary effort exhibited by employees in their jobs (Chopde et al., 2019). In the academic literature, a number of definitions have been provided.

Moreover, Kahn (1990) defines personal engagement as “the harnessing of organization members' selves to their work roles; in engagement, people employ and express themselves physically, cognitively, and emotionally during role performances." Personal disengagement refers to "the uncoupling of selves from work roles; in disengagement, people withdraw and defend themselves physically, cognitively, or emotionally during role performances" (p. 694). Thus, according to Kahn $(1990,1992)$. engagement means to be psychologically present when occupying and performing an organizational role. Namubiru (2019) also defines engagement as a psychological presence and states that it involves two critical components: attention and absorption. Attention refers to "cognitive availability and the amount of time one spends thinking about a role," while absorption "means being engrossed in a role and refers to the intensity of one's focus on a role." Burnout researchers define engagement as the opposite or positive antithesis of burnout (Torabi \& Nadali, 2016). According to Torabi \& Nadali (2016), engagement is characterized by energy, involvement, and efficacy, the direct opposite of the three burnout dimensions of exhaustion, cynicism, and inefficacy.

Additionally, research on burnout and engagement has found that the core dimensions of burnout (exhaustion and cynicism) and engagement (vigor and dedication) are opposites of each other (Nimon \& Shuck, 2020). Mäkikangas et al. (2017) define engagement "as a positive, fulfilling, work-related state of mind that is characterized by vigor, dedication, and absorption."; Further, they state that engagement is not a momentary and specific state, but rather, it is "a more persistent and pervasive affective-cognitive state that is not focused on any particular object, event, individual, or behavior." In the academic literature, engagement is related to but distinct from other organizational behavior constructs. 
For example, Rao (2017) stated that: engagement contains many of the elements of both commitment and OCB but is by no means a perfect match with either. In addition, neither commitment nor OCB reflects sufficiently two aspects of engagement - its two-way nature and the extent to which engaged employees are expected to have an element of business awareness. Given the limited research on employee engagement, there has been little in the way of model or theory development. However, there are two streams of research that provide models of employee engagement. In his qualitative study on the psychological conditions of personal engagement and disengagement at work, Kahn (1990) interviewed summer camp counselors and organizational members of an architecture firm about their moments of engagement and disengagement at work. Kahn (1990) found that there were three psychological conditions associated with engagement or disengagement at work: meaningfulness, safety, and availability. In other words, workers were more engaged at work in situations that offered them more psychological meaningfulness and psychological safety, and when they were more psychologically available (Abdulrab et al., 2017). In a study to empirically test Kahn's (1990) model, Soares \& Mosquera (2019)found that meaningfulness, safety, and availability were significantly related to engagement. They also found that job enrichment and role fit were positive predictors of meaningfulness; rewarding co-worker and supportive supervisor relations were positive predictors of safety while adherence to co-worker norms and self-consciousness was negative predictors; and resources available was a positive predictor of psychological availability while participation in outside activities was a negative predictor. The other model of engagement comes from the burnout literature which describes job engagement as the positive antithesis of burnout noting that burnout involves the erosion of engagement with one's job (Maslach, 2018). According to Maslach (2018), six areas of work-life lead to burnout and engagement: workload, control, rewards and recognition, community and social support, perceived fairness, and values. They argue that job engagement is associated with a sustainable workload, feelings of choice and control, appropriate recognition and reward, a supportive work community, fairness and justice, and meaningful and valued work. Like burnout, engagement is expected to mediate the link between these six work-life factors and various work outcomes. Although both Kahn's (1990) and Maslach's (2018) models indicate the psychological conditions or antecedents that are necessary for engagement, they do not fully explain why individuals will respond to these conditions with varying degrees of engagement. A stronger theoretical rationale for explaining employee engagement can be found in social exchange theory (SET). SET argues that obligations are generated through a series of interactions between parties who are in a state of reciprocal interdependence. A basic tenet of SET is that relationships evolve over time into trusting, loyal, and mutual commitments as long as the parties abide by certain "rules" of exchange (Cropanzano \& Mitchell, 2005). Rules of exchange usually involve reciprocity or repayment rules such that the actions of one-party lead to a response or actions by the other party. For example, when individuals receive economic and socioemotional resources from their organization, they feel obliged to respond in kind and repay the organization (Cropanzano \& Mitchell, 2005). This is consistent with Sundari \& Narayanamma (2020) description of engagement as a two-way relationship between the employer and employee.

One way for individuals to repay their organization is through their level of engagement. That is, employees will choose to engage themselves to varying degrees and in response to the resources they receive from their organization. Bringing oneself more fully into one's work roles and devoting greater amounts of cognitive, emotional, and physical resources is a very profound way for individuals to respond to an organization's actions. It is more difficult for employees to vary their levels of job performance, given that performance is often evaluated and used as the basis for compensation and other administrative decisions. Thus, employees are more likely to exchange their engagement for resources and benefits provided by their organization.

In summary, SET provides a theoretical foundation to explain why employees choose to become more or less engaged in their work and organization. The conditions of engagement in both Kahn's (1990) and Maslach's (2018) models can be considered economic and socioemotional exchange resources within SCT. When employees receive these resources from their organization, they feel obliged to repay the organization with greater levels of engagement. In terms of Kahn's (1990) definition of engagement, employees feel obliged to bring themselves more deeply into their role performances as repayment for the resources they receive from their organization. When the organization fails to provide these resources, individuals are more likely to withdraw and disengage themselves from their roles. Thus, the amount of cognitive, emotional, and physical resources that an individual is prepared to devote in the performance of one's work roles is contingent on the economic and socioemotional resources received from the organization.

\section{Conceptual Framework of the Study}

The study proposed a conceptual framework of the four dimensions of the leader's emotional intelligence and employee engagement, as seen in Figure 1. In the literature review illustration, the relationship between the two variables is discussed, which provides evidence for the hypothesized that leadership emotional intelligence has a significant influence on the employees' engagement. The proposed hypotheses for this study are the following. 


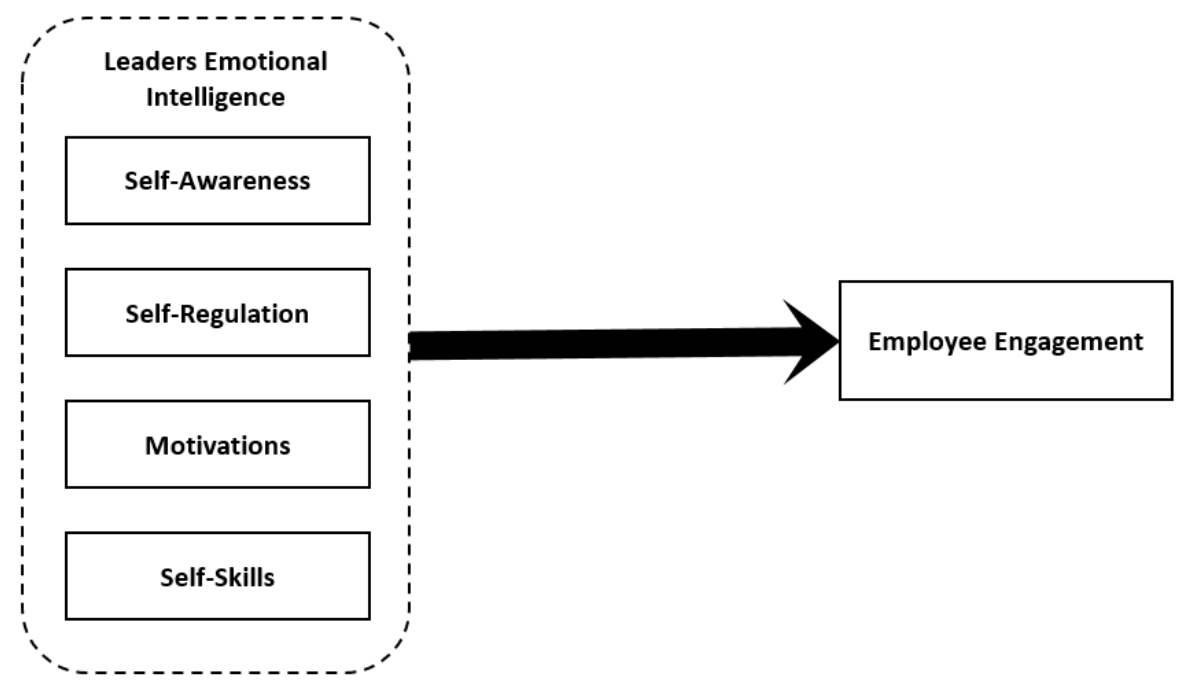

Fig. 1. Conceptual Framework of the Study

- H1: Self-awareness has a significant influence on employees' engagement among private-sector employees in the Kingdom of Bahrain

- H2: Self-regulation has a significant influence on employees' engagement among private-sector employees in the Kingdom of Bahrain

- H3: Motivation has a significant influence on employees' engagement among private-sector employees in the Kingdom of Bahrain

- H4: Self-skills has a significant influence on employees' engagement among private-sector employees in the Kingdom of Bahrain

\section{Research Methodology}

The research is descriptive, that is, to further study a topic that lacks research and knowledge in specific areas. The study uses a quantitative data analysis method because it is more suitable for this kind of hypothesis where we want to examine the relationship between two variables. The researcher used quantitative research to evaluate information that is collected and determine the outcomes or the results. Typically, quantitative research offers a piece of precise and numerical information. It has allowed the conversion of important data into easily quantifiable graphs as well as charts. It has permitted significant accuracy as well as the objectivity of results, which are relatively reliant on the researcher. In simple terms, the quantitative method enables that researcher to use a series of styles that provide data that is projectable to most of the population.

The researcher involves two main methods of data collection; they are primary and secondary sources of data. Primary research was conducted in the form of a questionnaire that was randomly distributed to gather new information. This research's primary source of data is the questionnaire (see appendix). The questionnaire included a number of questions directed to individuals in regard to the research topic to gather sufficient reliable information for the analysis. Secondary research was involved by gathering past papers and studies conducted by different authors who were published in journals and magazines.

This study is to examine whether there is a relationship between the two variables "leaders emotional intelligence and employee engagement" in the private sector in Bahrain. The study involves a questionnaire as a research technique in gathering information. Random sampling is a wide range of sampling techniques that alleviate systematic prejudice in research. It is important in the manner that it allows the researcher to make inferences concerning everything that has been observed from the sample. The sampling method chosen is Simple Random Sampling (SRS). The questionnaire was set online, and therefore, the questionnaire was distributed in a random manner. A total of 117 questionnaires were collected, though only 108 questionnaires were complete and viable to be used in the study. The viable response rate is, therefore, $92 \%$.

The questionnaire was divided into three parts, and the first offer a few demographic questions to gain respondent background information; part two is focused on Leaders' Emotional Intelligence, and part three is focused on employee engagement. For the analysis of the responses, the questionnaire involves 5-point a Likert scale. The Likert scale is as 1: Strongly disagree, 2: Disagree, 3: Neutral/Moderately Agree, 4: Agree \& 5: Strongly Agree. 


\section{Findings}

\subsection{Demographic Data Analysis}

The first part of the questionnaire required respondents to answer basic demographic questions. Based on the results of the questionnaire, out of a total of 228 respondents, $48 \%$ of respondents were male, while the other $52 \%$ were female. The majority of the participants hold Bachelor's degrees, making $72 \%$ of total respondents; $14 \%$ of respondents hold master's degrees; $11 \%$ of respondents hold high school certificates, while the final $3 \%$ are Ph.D. holders. Moreover, $45 \%$ of the respondents were aged between (18 to 29 ), $41 \%$ of respondents aged between (29 to 39), $11 \%$ aged between (40 to 50 ), and the final $3 \%$ were between the age (50 to 60). Finally, in terms of years of service, $46 \%$ had less than five years of experience; $24 \%$ had 5-10 years of experience; $17 \%$ had $11-15$ years of experience; $5 \%$ had $16-20$ years of experience; $5 \%$ had 21-25 years of experience, and 3\% had 26-30 years of experience.

\subsection{Reliability Analysis}

Table 1 shows the inter-items correlations for the leaders' emotional intelligence scale. Results indicate that Q1, Q2, Q3, Q5, Q6, Q7, Q8, Q9, Q10, Q11, Q12, Q13, Q14, Q15, Q16, and Q17 are well correlated $(0.575>0.3,0.578>0.3$, $0.535>0.3,0.575>0.3,0.516>0.3,0.515>0.3,0.502>0.3,0.576>0.3,0.539>0.3,0.486>0.3,0.370>0.3,0.643$ $>0.3,0.519>0.3,0.601>0.3$, and $0.582>0.3)$, except for $\mathrm{Q} 4$, which has a lower correlation $(0.285>0.3)$ and therefore, doesn't correlate well with the other questions.

Table 2 shows that each of the items Q1, Q2, Q3, Q5, Q6, Q7, Q8, Q9, Q10, Q11, Q12, Q13, Q14, Q15, Q16, and Q17 correlate well with the overall total correlation of other items $(0.682>0.5,0.755>0.5,0.765>0.5,0.784>0.5,0.788>$ $0.5,0.790>0.5,0.813>0.5,0.720>0.5,0.800>0.5,0.684>0.5,0.763>0.5,0.550>0.5,0.849>0.5,0.787>0.5$, $0.831>0.5,0.766>0.5)$, except for $\mathrm{Q} 4$, which has a lower correlation of ( $0.299>0.5)$.

Moreover, as shown in Table 2, although Cronbach's Alpha would increase from 0.955 to 0.960 if Q4 were deleted, the increase is very minor, and therefore, there is no statistical reason to drop the question. All the questions are useful and contribute to the reliability of the study.

Table 1. Inter-Item Correlation Matrix for Leaders' Emotional Intelligence

\begin{tabular}{lllllllllllllllllll}
\hline & Q1 & Q2 & Q3 & Q4 & Q5 & Q6 & Q7 & Q8 & Q9 & Q10 & Q11 & Q12 & Q13 & Q14 & Q15 & Q16 & Q17 \\
\hline Q1 & 1.000 & .575 & .578 & .285 & .535 & .575 & .516 & .515 & .502 & .576 & .539 & .486 & .370 & .643 & .519 & .601 & .582 \\
Q2 & .575 & 1.000 & .642 & .286 & .608 & .629 & .554 & .640 & .447 & .631 & .519 & .605 & .387 & .668 & .662 & .744 & .635 \\
Q3 & .578 & .642 & 1.000 & .203 & .601 & .647 & .680 & .703 & .649 & .659 & .563 & .635 & .366 & .666 & .567 & .636 & .581 \\
Q4 & .285 & .286 & .203 & 1.000 & .184 & .269 & .364 & .237 & .191 & .296 & .166 & .197 & .294 & .225 & .147 & .219 & .233 \\
Q5 & .535 & .608 & .601 & .184 & 1.000 & .688 & .620 & .728 & .605 & .637 & .470 & .706 & .394 & .767 & .652 & .747 & .629 \\
Q6 & .575 & .629 & .647 & .269 & .688 & 1.000 & .732 & .659 & .577 & .633 & .610 & .604 & .407 & .759 & .665 & .620 & .549 \\
Q7 & .516 & .554 & .680 & .364 & .620 & .732 & 1.000 & .720 & .663 & .629 & .559 & .614 & .401 & .734 & .611 & .655 & .586 \\
Q8 & .515 & .640 & .703 & .237 & .728 & .659 & .720 & 1.000 & .552 & .720 & .553 & .681 & .459 & .666 & .692 & .768 & .603 \\
Q9 & .502 & .447 & .649 & .191 & .605 & .577 & .663 & .552 & 1.000 & .553 & .566 & .527 & .591 & .628 & .638 & .570 & .558 \\
Q10 & .576 & .631 & .659 & .296 & .637 & .633 & .629 & .720 & .553 & 1.000 & .601 & .701 & .472 & .671 & .628 & .671 & .687 \\
Q11 & .539 & .519 & .563 & .166 & .470 & .610 & .559 & .553 & .566 & .601 & 1.000 & .540 & .537 & .653 & .551 & .474 & .514 \\
Q12 & .486 & .605 & .635 & .197 & .706 & .604 & .614 & .681 & .527 & .701 & .540 & 1.000 & .321 & .758 & .622 & .698 & .652 \\
Q13 & .370 & .387 & .366 & .294 & .394 & .407 & .401 & .459 & .591 & .472 & .537 & .321 & 1.000 & .367 & .536 & .436 & .495 \\
Q14 & .643 & .668 & .666 & .225 & .767 & .759 & .734 & .666 & .628 & .671 & .653 & .758 & .367 & 1.000 & .696 & .745 & .682 \\
Q15 & .519 & .662 & .567 & .147 & .652 & .665 & .611 & .692 & .638 & .628 & .551 & .622 & .536 & .696 & 1.000 & .795 & .633 \\
Q16 & .601 & .744 & .636 & .219 & .747 & .620 & .655 & .768 & .570 & .671 & .474 & .698 & .436 & .745 & .795 & 1.000 & .729 \\
Q17 & .582 & .635 & .581 & .233 & .629 & .549 & .586 & .603 & .558 & .687 & .514 & .652 & .495 & .682 & .633 & .729 & 1.000 \\
\hline
\end{tabular}

Table 2. Item-Total Statistics for Leaders' Emotional Intelligence

\begin{tabular}{llcccc}
\hline & $\begin{array}{l}\text { Scale Mean } \\
\text { Deleted }\end{array}$ & $\begin{array}{c}\text { if } \\
\text { Deleted }\end{array}$ & Correlation & $\begin{array}{c}\text { Item-TotalSquared } \\
\text { Correlation }\end{array}$ & \multicolumn{2}{c}{$\begin{array}{c}\text { MultipleCronbach's Alpha if Item } \\
\text { Deleted }\end{array}$} \\
\hline Q1 & 56.8889 & 245.184 & .682 & .543 & .953 \\
Q2 & 56.6204 & 242.219 & .755 & .670 & .951 \\
Q3 & 56.5556 & 241.053 & .765 & .694 & .951 \\
Q4 & 57.1481 & 256.763 & .299 & .282 & .960
\end{tabular}




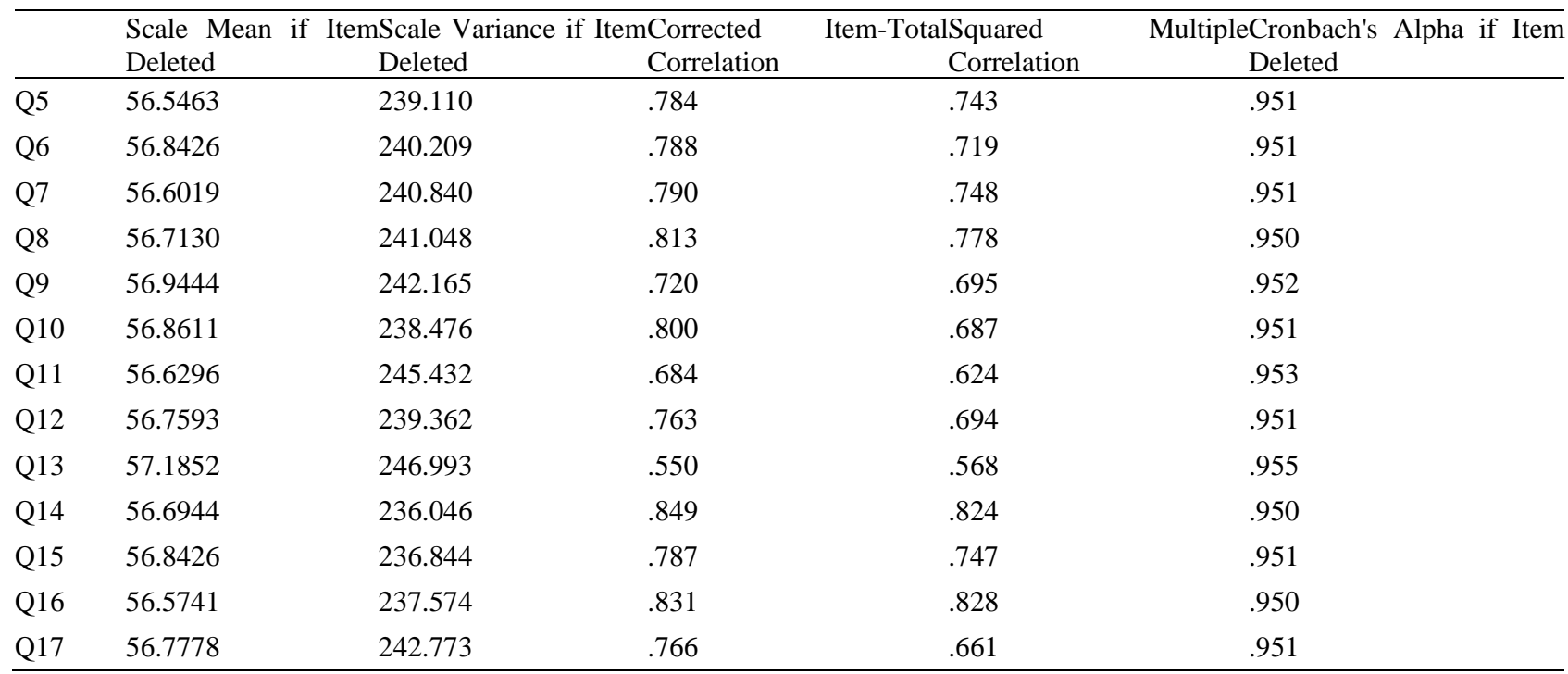

Employee engagement is explained through 12 questions. Table 3 shows that the overall alpha of the Employee Engagement is 0.909 , which indicates strong internal consistency of the questions. Table 4.5 indicates that Q18, Q19, Q20, Q21, Q22, Q23, Q25, Q26, Q27, Q28, and Q29 are well correlated $(0.806>0.3,0.472>0.3,0.517>0.3,0.397>$ $0.3,0.470>0.3,0.376>0.3,0.440>0.3,0.341>0.3,0.517>0.3$ ), except for Q4 and Q29, which have lower correlation $(0.103>0.3,0.198>0.3)$ and therefore, don't correlate well with the other questions.

Table 4 shows that each of the items Q18, Q19, Q20, Q21, Q22, Q23, Q24, Q25, Q26, Q27, Q28, and Q29 correlate well with the overall total correlation of other items $(0.598>0.5,0.748>0.5,0.657>0.5,0.703>0.5,0.709>0.5,0.678$ $>0.5,0.557>0.5,0.710>0.5,0.682>0.5,0.602>0.5,0.535>0.5,0.546>0.5)$.

Moreover, as shown in Table 4.6, if any question were deleted, then Cronbach's Alpha would decrease, and therefore there is no statistical reason to drop the question. All the questions are useful and contribute to the reliability of the study.

Table 3. Inter-Item Correlation Matrix for Employee Engagement

\begin{tabular}{lllllllllllll}
\hline & Q18 & Q19 & Q20 & Q21 & Q22 & Q23 & Q24 & Q25 & Q26 & Q27 & Q28 & Q29 \\
\hline Q18 & 1.000 & .806 & .472 & .517 & .397 & .470 & .103 & .376 & .440 & .341 & .517 & .198 \\
Q19 & .806 & 1.000 & .537 & .697 & .476 & .674 & .297 & .496 & .527 & .343 & .467 & .358 \\
Q20 & .472 & .537 & 1.000 & .608 & .496 & .359 & .514 & .458 & .509 & .456 & .337 & .413 \\
Q21 & .517 & .697 & .608 & 1.000 & .465 & .548 & .456 & .493 & .555 & .350 & .299 & .442 \\
Q22 & .397 & .476 & .496 & .465 & 1.000 & .638 & .528 & .648 & .522 & .502 & .375 & .502 \\
Q23 & .470 & .674 & .359 & .548 & .638 & 1.000 & .387 & .589 & .504 & .317 & .382 & .408 \\
Q24 & .103 & .297 & .514 & .456 & .528 & .387 & 1.000 & .605 & .399 & .476 & .311 & .408 \\
Q25 & .376 & .496 & .458 & .493 & .648 & .589 & .605 & 1.000 & .562 & .574 & .345 & .418 \\
Q26 & .440 & .527 & .509 & .555 & .522 & .504 & .399 & .562 & 1.000 & .545 & .384 & .399 \\
Q27 & .341 & .343 & .456 & .350 & .502 & .317 & .476 & .574 & .545 & 1.000 & .451 & .433 \\
Q28 & .517 & .467 & .337 & .299 & .375 & .382 & .311 & .345 & .384 & .451 & 1.000 & .385 \\
Q29 & .198 & .358 & .413 & .442 & .502 & .408 & .408 & .418 & .399 & .433 & .385 & 1.000 \\
\hline
\end{tabular}

Table 4. Item-Total Statistics for Employee Engagement

\begin{tabular}{llccccc}
\hline & $\begin{array}{l}\text { Scale Mean } \\
\text { Deleted }\end{array}$ & $\begin{array}{c}\text { if } \\
\text { Deleted }\end{array}$ & $\begin{array}{c}\text { Item Corrected } \\
\text { Derrelation }\end{array}$ & $\begin{array}{c}\text { Item-TotalSquared } \\
\text { Correlation }\end{array}$ & $\begin{array}{c}\text { MultipleCronbach's } \\
\text { Item Deleted }\end{array}$ \\
\hline Q18 & 42.4630 & 84.662 & .598 & .753 & .904 \\
Q19 & 42.3333 & 83.252 & .748 & .814 & .896 \\
Q20 & 42.1667 & 83.355 & .657 & .544 & .901 \\
Q21 & 42.2130 & 84.730 & .703 & .627 & .898 \\
Q22 & 41.8333 & 83.991 & .709 & .608 & .898 \\
Q23 & 42.0926 & 83.244 & .678 & .646 & .899 \\
Q24 & 41.7685 & 87.806 & .557 & .568 & .905 \\
Q25 & 41.7222 & 85.791 & .710 & .621 & .898
\end{tabular}




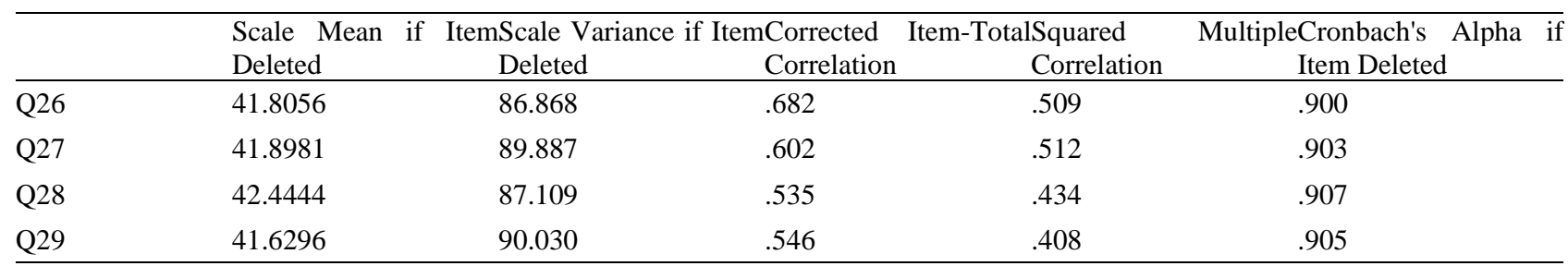

After ensuring the inter-item correlations' reliability, Cronbach's Alpha is measured for the different construct, as seen in Table 5. Results show that all values are above 0.7 and almost 0.9 , which revealed that the different scales have an acceptable level of reliability.

Table 4. Cronbach's Alpha for the Variables

\begin{tabular}{ccccc}
\hline Variable/Construct & Abbreviation & Cronbach's Alpha & $\begin{array}{c}\text { Cronbach's Alpha Based } \\
\text { on Standardized Items }\end{array}$ & N of Items \\
\hline Employees' Engagement & EE & 0.909 & 0.910 & 12 \\
Leaders Emotional & LEI & 0.944 & 0.955 & 17 \\
Intelligence & SA & 0.901 & 0.903 & 6 \\
Self-Awareness & SR & 0.898 & 0.902 & 6 \\
Self-Regulation & MO & 0.923 & 0.933 & 6 \\
Motivations & SS & 0.910 & 0.914 & 5 \\
Self-Skills & & & & \\
\hline
\end{tabular}

\subsection{Pearson's correlation Analysis}

The researcher performed a correlation analysis to measure the research topic's correlation before conducting a regression analysis to accept/reject the proposed hypothesis. Here a correlation test is conducted between the different variables in the conceptual framework.

Table 5. Correlations between the Proposed Variables

\begin{tabular}{|c|c|c|c|c|c|}
\hline & $\mathrm{EE}$ & SA & SR & $\mathrm{MO}$ & $\mathrm{SS}$ \\
\hline \multirow{3}{*}{$\mathrm{EE}$} & 1 & .760 & .459 & .373 & .649 \\
\hline & & .000 & .000 & .000 & .000 \\
\hline & 108 & 108 & 108 & 108 & 108 \\
\hline \multirow{3}{*}{ SA } & .760 & 1 & .384 & .331 & .599 \\
\hline & .000 & & .000 & .000 & .000 \\
\hline & 108 & 108 & 108 & 108 & 108 \\
\hline \multirow{3}{*}{ SR } & .459 & .384 & 1 & .228 & .291 \\
\hline & .000 & .000 & & .001 & .000 \\
\hline & 108 & 108 & 108 & 108 & 108 \\
\hline \multirow{3}{*}{ MO } & .373 & .331 & .228 & 1 & .261 \\
\hline & .000 & .000 & .001 & & .000 \\
\hline & 108 & 108 & 108 & 108 & 108 \\
\hline \multirow{3}{*}{ SS } & .649 & .599 & .291 & .261 & 1 \\
\hline & .000 & .000 & .000 & .000 & \\
\hline & 108 & 108 & 108 & 108 & 108 \\
\hline
\end{tabular}

As presented in table 5, the result of Pearson's Correlation between the four dimensions of Leaders' Emotional Intelligence and Employee Engagement (EE) shows that there is a positive correlation at a rate that ranges between $r=$ 0.266 and $r=0.760$, with a significance level at $10 \%$. The results show that all variables have significant correlations with each other. 


\subsection{Regression Analysis}

The regression analysis is the final test conducted for the research. This study's regression model has four predictors; self-awareness, self-regulation, motivation, and self-skills, to the dependent variable, employees' engagement. Table 6 indicates that the coefficient determination $\mathrm{R}^{2}$ is 0.670 , showing that $67.0 \%$ of the dependent variable variation is explained as a portion variation of the independent variables. This result is significant as it is shown in Table 7 ( $p$-value $=0.000<0.01)$. Moreover, Table 8 shows that there is evidence that the four independent variables have significant relationships with the dependent variable. Self-awareness (SA) has the strongest significant relationship with a $\mathrm{p}$-value $=$ 0.000 and path coefficient $=0.679$; self-skills $(\mathrm{SS})$ has the second significant relationship with a p-value $=0.000$ and path coefficient $=0.318$; self-regulation $(\mathrm{SR})$ has the third significant relationship with a $p$-value $=0.000$ and path coefficient $=0.177$; and motivation $(\mathrm{MO})$ has the least significant relationship with a $\mathrm{p}$-value $=0.020$ and path coefficient $=0.109$.

Table 6. Model Summary Analysis

\begin{tabular}{lllll}
\hline Model & $\mathrm{R}$ & R Square & Adjusted R Square & Std. The error of the Estimate \\
\hline 1 & $.819^{\mathrm{a}}$ & .670 & .664 & .57852 \\
\hline
\end{tabular}

a. Predictors: (Constant), SS, MO, SR, SA

Table 7. ANOVA Analysis

\begin{tabular}{lllllll}
\hline Model & & Sum of Squares & df & Mean Square & F & Sig. \\
\hline \multirow{2}{*}{1} & Regression & 144.977 & 4 & 36.244 & $.000^{\mathrm{b}}$ \\
& Residual & 71.288 & 213 & .335 & \\
& Total & 216.264 & 217 & & \\
\hline
\end{tabular}

a. Dependent Variable: EE

b. Predictors: (Constant), SS, MO, SR, SA

Table 8. Coefficients Analysis

\begin{tabular}{|c|c|c|c|c|c|c|}
\hline \multirow{2}{*}{\multicolumn{2}{|c|}{ Model }} & \multicolumn{2}{|c|}{ Unstandardized Coefficients } & \multirow{2}{*}{$\begin{array}{l}\text { Standardized } \\
\text { Coefficients } \\
\text { Beta }\end{array}$} & \multirow[t]{2}{*}{$\mathrm{t}$} & \multirow[t]{2}{*}{ Sig. } \\
\hline & & B & Std. Error & & & \\
\hline \multirow{5}{*}{1} & (Constant) & -.553 & .214 & & -2.585 & .010 \\
\hline & $\mathrm{SA}$ & .679 & .071 & .498 & 9.580 & .000 \\
\hline & SR & .177 & .046 & .165 & 3.837 & .000 \\
\hline & MO & .109 & .047 & .099 & 2.345 & .020 \\
\hline & SS & .318 & .057 & .276 & 5.591 & .000 \\
\hline
\end{tabular}

a. Dependent Variable: EE

\section{Discussions and Conclusions}

Based on the illustrated findings from regression analysis and correlations, we can conclude that hypothesis 1 is accepted, and self-awareness has the strongest path coefficient and correlation as well. Similar, hypothesis 2 is accepted, and self-regulation has the least path coefficient and correlation as well. Similarly, hypothesis 3 is accepted, and the motivation has the third path coefficient and correlation. Similarly, hypothesis 4 is accepted, and the self-skills have the second path coefficient and correlation as well. Results show that the four dimensions of leaders' emotional intelligence are significant and impact employee engagement but with different levels of impact.

Managers, especially in human resource management, must develop practices to increase the leaders' self-awareness because one unit's increment can improve the engagement by 0.679 . While the other four dimensions are also important and must be increased, the three impacts together are less than the self-awareness impact.

\section{Limitations and Future Research}

Though the study contributes well to the field of knowledge, the study still has limitations associated with it. First, it was hard to target a specific gender, though at first, the majority of responses were from females, the results changed. Second, there is limited literature regarding the research topic as few papers can be found linking the variables together. Moreover, it was difficult to measure the rate of employee engagement due to lack of resources and lack of time. Furthermore, this research represents the relationship between leadership and employee engagement in Bahrain's private sector only, limiting the data and results. Therefore, future studies may look into examining the relationship between 
leadership and employee engagement in the public sector and the extent to which employee engagement is affected. Future studies can focus on other constructs related to Leaders' Emotional Intelligence, other than employee engagement. Future studies should also be conducted in different countries and markets to gain more knowledge regarding the research topic. The research can also be specified to a specific gender to have more specific and accurate results and whether the gender factor can make a difference in the results.

\section{References}

Abdulrab, M., Zumrah, A. R., Almaamari, Q., \& Altahitah, A. (2017). The role of psychological empowerment on work engagement: The development of the conceptual framework. International Journal of Business Management and Economic Research, 8(6), 1157-1163.

Al-Maamari, Q. A., Kassim, R. N., Raju, V., Al-Tahitah, A., Ameen, A., Abdulrab, M., \& Abdulrab, M. (2018). Factors affecting individual readiness for change: A conceptual framework. International Journal of Management and Human Science, 2 (1), $13-18$.

Alzgool, M. (2019). Nexus between green HRM and green management towards fostering green values. Management Science Letters, 9(12), 20732082.

AlZgool, M. R. H. (2020). Understanding the Dynamic Nexus between Green Human Resource Management and Environmental Performance: The Moderating Role of Green Leaders' Emotional Intelligence in the Pharmaceutical Sector of Bahrain. Systematic Reviews in Pharmacy, 11(2), 777-785.

Alzyoud, A. A. Y., Ahmed, U., AlZgool, M. R. H., \& Pahi, M. H. (2019). Leaders' emotional intelligence and employee retention: Mediation of job satisfaction in the hospitality industry. International Journal of Financial Research, 10(3), 1-10.

Buil, I., Martínez, E., \& Matute, J. (2019). Transformational leadership and employee performance: The role of identification, engagement and proactive personality. International Journal of Hospitality Management, 77, 64-75.

Choi, J., Chung, G., Sung, S., Butt, A. N., Soliman, M., \& Chang, J. (2015). Does emotional intelligence matter in interpersonal processes? The mediating role of emotion management. Seoul Journal of Business.

Chopde, P. T., Singh, V., \& Pande, M. (2019). Factors Influencing Employee Engagement in Telecom Organisations.

Choudhary, N., Naqshbandi, M. M., Philip, P. J., \& Kumar, R. (2017). Employee job performance. Journal of Management Development.

Clarke, N. (2018). Relational leadership: Theory, practice and development. Routledge.

Cropanzano, R., \& Mitchell, M. S. (2005). Social exchange theory: An interdisciplinary review. Journal of Management, 31(6), 874-900.

Goleman, D. (1998). What makes a leader? Harvard Business Review" November-December.

Goleman, Daniel. (2001). An EI-based theory of performance. The Emotionally Intelligent Workplace: How to Select for, Measure, and Improve Emotional Intelligence in Individuals, Groups, and Organizations, 1, $27-44$.

Gupta, M. (2015). A study on employees perception towards employee engagement. Globsyn Management Journal, 9(1/2), 45-51.

Hoch, J. E., Bommer, W. H., Dulebohn, J. H., \& Wu, D. (2018). Do ethical, authentic, and servant leadership explain variance above and beyond transformational leadership? A meta-analysis. Journal of Management, 44(2), 501-529.

Johnson, C. E., \& Hackman, M. Z. (2018). Leadership: A communication perspective. Waveland Press.

Kahn, W. A. (1990). Psychological conditions of personal engagement and disengagement at work. Academy of Management Journal, 33(4), 692724

LEADERSHIP, T., \& DERINDAG, O. F. (2020). CHAPTER FOUR TRANSFORMATIONAL LEADERSHIP O. FARUK DERINDAG1. $A$ Handbook of Leadership Styles, 84.

Mäkikangas, A., Hyvönen, K., \& Feldt, T. (2017). The energy and identification continua of burnout and work engagement: Developmental profiles over eight years. Burnout Research, 5, 44-54.

Maslach, C. (2018). Job burnout in professional and economic contexts. Diversity in Unity: Perspectives from Psychology and Behavioral Sciences, $11-15$.

Mozammel, S., Ahmed, U., Slade, H., \& Zaman, F. (2018). Digging Deep in StudentsEngagement in Bahrain: Contributions From Academic SelfEfficacy and Academic Resilience. International Journal of Management and Business Research, 8(1), 136-147.

Namubiru, S. (2019). Decent work environment, employee engagement and turnover intentions among the employees of Kampala Capital City Authority. Makerere University.

Nimon, K., \& Shuck, B. (2020). Work engagement and burnout: Testing the theoretical continuums of identification and energy. Human Resource Development Quarterly, 31(3), 301-318.

Prins, A. (2006). Emotional intelligence and leadership in corporate management: A fortigenic perspective. University of the Free State.

Rao, I. (2017). Work-life balance for sustainable human development: Cultural intelligence as enabler. Journal of Human Behavior in the Social Environment, 27(7), 706-713.

Schoemaker, P. J. H., Heaton, S., \& Teece, D. (2018). Innovation, dynamic capabilities, and leadership. California Management Review, 61(1), 1542.

Soares, M. E., \& Mosquera, P. (2019). Fostering work engagement: The role of the psychological contract. Journal of Business Research, 101, 469476.

SUNDARI, N. U. D., \& NARAYANAMMA, D. R. P. L. (2020). A STUDY ON EMPLOYEE ENGAGEMENT: THE KEY TO IMPROVING PERFORMANCE. IJRAR-International Journal of Research and Analytical Reviews (IJRAR), 7(1), 394-403.

Torabi, M., \& Nadali, I. Z. (2016). When does spiritual intelligence particularly predict job engagement? The mediating role of psychological empowerment. Iranian Journal of Nursing and Midwifery Research, 21(6), 589.

Turner, P. (2019). Employee engagement in contemporary organizations: Maintaining high productivity and sustained competitiveness. Springer.

Wambura, M. (2020). Effect of workers' engagement on the organization's effectiveness. Mzumbe University.

Wen, J., Huang, S. S., \& Hou, P. (2019). Emotional intelligence, emotional labor, perceived organizational support, and job satisfaction: A moderated mediation model. International Journal of Hospitality Management, 81, 120-130.

Zhou, Z., Luo, B. N., \& Tang, T. L. (2018). Corporate social responsibility excites 'exponential'positive employee engagement: The Matthew effect in CSR and sustainable policy. Corporate Social Responsibility and Environmental Management, 25(4), 339-354. 